\title{
O passeio de Rosinha: articulando saberes sociais e biológicos na infância por meio da literatura
}

\author{
Tatiana Pereira da Silva" \\ Paula Teixeira Araujo" \\ Luís Paulo de Carvalho Piassi"*** \\ Emerson Izidoro dos Santos ${ }^{* * * * *}$
}

\section{Resumo}

Neste artigo, buscamos discutir a possibilidade de abordagem de temas sociais de forma articulada com saberes biológicos nos anos iniciais de escolarização usando como recurso o livro de literatura infantil. A escolha por esse tipo de material deve-se ao fato de ser amplamente empregado no ensino dirigido a esse público. Apresentamos um panorama histórico da produção dessa modalidade de literatura e, em seguida, exemplificamos uma proposta a partir da análise, com base em elementos da semiótica greimasiana, de uma obra específica de literatura infantil, levantando, a partir desta, diferentes temáticas sociais que podem ser abordadas no contexto de sala de aula e que têm relação com o dia a dia das crianças. Nossas análises demonstraram ambivalências entre as representações dos animais e as temáticas científicas, mas também em relação ao livro infantil enquanto objeto educacional. Por fim, concluí- mos que a articulação de diferentes campos de saberes no desenvolvimento de uma atividade contribui para uma educação menos compartimentalizada e para a construção de um conhecimento mais articulado.

Palavras-chave: Conhecimento sociocientífico. Literatura infantil. Polivalência.
* Doutoranda em Educação pela Faculdade de Educação da Universidade de São Paulo. E-mail: tps.tati@gmail. com

** Mestra em Filosofia pela Escola de Artes, Ciências e Humanidades da Universidade de São Paulo. E-mail: paraujo@usp.br

*** Professor doutor da Escola de Artes, Ciências e Humanidades e do Programa de Pós-Graduação em Estudos Culturais da Universidade de São Paulo. E-mail: lppiassi@usp.br

${ }^{* * * * *}$ Professor doutor da Escola de Filosofia, Letras e Ciências Humanas da Unifesp. E-mail: mson@usp.br

Data de submissão: jul. 2017 - Data de aceite: mar. 2018 http://dx.doi.org/10.5335/rdes.v14i1.7285 


\section{Introdução}

O presente artigo resulta de um estudo sobre o uso do livro infantil ilustrado no ensino de ciências nos anos iniciais do ensino fundamental. Entre os principais pressupostos estão: (a) o livro infantil é um material bastante presente e acessível nas escolas em geral; (b) ele já é empregado por muitos professores no processo de alfabetização; (c) é relativamente fácil encontrar livros em que é possível explorar tópicos de ciências naturais; (d) ele desperta o interesse das crianças pelo livro e pela leitura; e (e) mesmo quando produzido sem essa intenção, possui características que 0 tornam especialmente interessante para a abordagem de conteúdos de ciência nos anos iniciais.

No Brasil, têm surgido alguns trabalhos específicos sobre o livro infantil ilustrado e sua relação com as ciências naturais e seu ensino. A professora e escritora Luana Linsingen realizou seu mestrado com um estudo específico sobre o uso do livro infantil no ensino de ciências, que, segundo ela, "fornece possibilidades de desvios daquilo que é oferecido pelo próprio texto, qual seja, o oferecimento da chance de se ler sobre a leitura" (LINSINGEN, 2008, p. 1, grifo do autor). A professora Fabiana Carvalho (2008), por sua vez, identifica a biologia em obras de Monteiro Lobato que, no entanto, não se enquadram exatamente no tipo de produção que estudamos neste texto. Giraldelli e Almeida (2008) realizaram um estudo sobre a leitura em aula de um livro infantil com estudantes de 9 a 10 anos de idade, o que permitiu

[...] uma construção de conceitos para as crianças, sem priorizar conteúdos específicos, mas considerando as relações ambientais como um todo (2008, p. 18).

Arlete Higashi (2010), professora de língua portuguesa da rede pública de ensino, estudou o livro infantil ilustrado sob a perspectiva da divulgação científica, concluindo que os títulos atuais

[...] privilegiam a reflexão e refração de assuntos pertinentes ao contexto político, cultural, social e científico dos nossos dias, propiciando, portanto, um constante diálogo entre esta esfera literária e as demais esferas de atividade (HIGASHI, 2010, p. 115).

Entre as pioneiras desse tipo de estudo está a especialista em livro infantil norte-americana Frances Smardo. A partir de exemplos encontrados em livros infantis, a autora comenta que eles podem ser "trampolins naturais para explorar com crianças pequenas as diferenças entre o que é real e o que é fantasia" (SMARDO, 1982, p. 267, tradução nossa). Em relação a isso, a autora pontua que, "às vezes, uma história que distorce ou ignora uma lei científica desperta o interesse da criança mais do que um livro factual" (SMARDO, 1982, p. 268, tradução nossa).

Ainda, a professora Becky Fisher (1980) descreveu um experimento em salas de aulas elementares no qual procurava confirmar a tese de que a literatura auxilia no aprendizado das ciências. Ela observa que, desde a década de 1960, 
alguns autores já defendiam esse ponto de vista:

Os sentimentos e atitudes das crianças em relação aos conceitos que elas aprendem são mais positivos quando a literatura é usada em conjunção com o livro didático. Tais sentimentos podem ser um fator motivador na retenção do aprendizado e no incentivo a estudos independentes futuros. As atitudes positivas que resultam possuem um efeito residual que ajuda a motivar os estudantes a prosseguir na exploração da ciência por si próprios (FISHER, 1980, p. 173, tradução nossa).

A especialista em livro infantil Pauline Zeece, em diversos artigos, sugere vários títulos em diversos conteúdos relacionados ao ensino de ciências (ZEECE, 1998, 1999a, 1999b; WELLS; ZEECE, 2007). Os professores Carol Butzow e John Butzow, especialistas em educação nas séries iniciais, possuem obras conhecidas voltadas para orientar professores de educação fundamental a empregar livros infantis ilustrados para o ensino de tópicos de ciência. Segundo eles,

[...] as crianças poderão encontrar mais facilidade em seguir ideias que são parte de uma história do que compreender os fatos como são apresentados nos livros didáticos (BUTZOW; BUTZOW, 2000, p. 4, tradução nossa).

Os autores defendem também que

uma história coloca fatos e conceitos em uma forma que encoraja as crianças a construir hipóteses, predizer eventos, coletar dados e testar a validade de eventos (BUTZOW; BUTZOW, 2000, p. 4, tradução nossa).

Sheila L. Goins (2004) escreveu uma tese de pós-doutoramento sobre os conteúdos botânicos de livros infantis ilustrados, com uma contribuição apro- fundada à metodologia de pesquisa e aplicação desse tipo de material nas aulas de ciências. As professoras Leigh Monhardt e Rebecca Monhardt (2000, 2006) também trabalharam com esse tema. No primeiro trabalho, as autoras investigaram a influência dos livros na formação de crenças e valores relativos ao meio ambiente, segundo elas, sem direcionar crenças e atitudes, mas "como veículo para que eles [os alunos] enxergassem mais que um lado de uma questão e desenvolver habilidades de pensamento crítico" (MONHARDT; MONHARDT, 2000, tradução nossa). Com a leitura do livro Tem uma coruja no chuveiro, elas perceberam que as crianças manifestaram simpatia à causa dos direitos dos animais, porém alertaram que a simples leitura proporcionou argumentos muito mais emocionais do que embasados em pressupostos científicos e constataram que, passados alguns meses, as crianças não estendiam, espontaneamente, esse posicionamento a outras situações cotidianas (MONHARDT; MONHARDT, 2000 , p. 180). No segundo artigo, as autoras trabalham em torno de sugestões de como usar os livros infantis para auxiliar no desenvolvimento de habilidades associadas ao aprendizado das ciências, tais como observação, classificação, inferência, comunicação, entre outras (MONHARDT; MONHARDT, 2006, p. 68). O principal papel reservado à literatura infantil, nesse caso, é o da produção de um contexto para as atividades desenvolvidas. 
Uma investigação detalhada, em sala de aula de terceira série, foi realizada nos Estados Unidos por pesquisadores em alfabetização (MORROW et al., 1997) juntamente com professores em serviço. Com crianças de diferentes origens étnicas, os pesquisadores elaboraram instrumentos de coleta de dados de aprendizagem em ciências e alfabetização, de forma articulada. Concluíram, então, que uma abordagem que integre ciência e literatura é mais efetiva (MORROW et al., 1997, p.72) e relataram que, quando foram entrevistados, os estudantes manifestaram especial entusiasmo pela abordagem. Os autores alertam, porém, que não foi possível determinar em que medida tais resultados estão associados a um efeito de "novidade", responsável por criar uma disposição naturalmente positiva em relação às atividades propostas (MORROW et al., 1997, p. 73).

Caroline Owens (2003), especialista em educação científica, também analisou o papel dos livros ilustrados, questionando sobre as possíveis distorções induzidas por textos e imagens não comprometidos com a precisão factual científica. Segundo ela, "a ficção e a fantasia podem ser confundidas com informações factuais pelas crianças pequenas" (OWENS, 2003, p. 60 , tradução nossa). Além disso, as histórias articulam a informação ao contexto social e emocional. O caminho, segundo a autora, é empregar a ficção com cuidado e critério para atingir objetivos determinados, em vez de usá-la simplesmente para tornar o aprendizado mais fácil ou divertido (OWENS, 2003, p. 60).
Diana Rice (2002) estudou o uso de livros comerciais no ensino de ciências para crianças, incluindo os livros ilustrados de ficção. Em um teste empregando livros sobre baleias, a autora demonstrou que as crianças eram incapazes de distinguir informações factuais corretas ou incorretas apresentadas nas histórias (RICE, 2002, p. 558). Rice (2002, p. 558) apresenta, ainda, estudos que mostram que concepções imprecisas adquiridas durante a infância tendem a se manter na vida adulta. Perspectivas similares são assumidas e demonstradas por outros autores (ROYCE; WILEY, 1996; SACKES; TRUNDLE; FLEVARES, 2009). Por conta disso, Rice (2002) defende a precisão conceitual como critério para a seleção de livros comerciais em sala de aula e apresenta outros critérios, geralmente sugeridos por pesquisadores: personagens críveis, passagem do tempo realista, igualdade de raça e gênero, qualidade das ilustrações, distinção entre fatos e fantasia e informação atualizada (RICE, 2002, p. 560). Talvez a contribuição mais importante de Rice seja a sugestão de como lidar com os livros, uma vez que, mesmo adotados todos esses critérios, ainda temos que contar com os livros disponíveis no mercado, e mesmo os melhores podem apresentar falhas conceituais e outros problemas. A autora detalha diversas formas de questionamento dos conteúdos dos livros, seja cotejando-os com outros livros, outras fontes de informação, experimentos práticos e análise crítica de conteúdo, mostrando que tais procedimentos po- 
dem perfeitamente ser realizados com crianças (RICE, 2002, p. 562).

Considerando as discussões apresentadas, buscaremos abordar o livro infantil ilustrado, em suas múltiplas aproximações, como agente da articulação possível entre temáticas sociais e políticas das ciências naturais. Para tal discussão, analisaremos o livro infantil $O$ passeio de Rosinha (HUTCHINS, 2004) e exemplos de seus desdobramentos em possibilidades didáticas. A análise da história busca apontar elementos que se aproximem de conteúdos da ciência e apontem possibilidades de intervenções didáticas no ensino fundamental.

O livro infantil está presente no espaço escolar e é valorizado por professores em diferentes atividades do cotidiano, essencialmente pela importância dada à leitura e à alfabetização, portanto, articular seu aproveitamento com questões sociocientíficas pode ser uma maneira de enriquecer as relações estabelecidas entre a criança e o livro, nas interfaces existentes no âmbito da leitura e da ciência. Considera-se, ainda, a possibilidade de aproximar a ciência de práticas significativas imersas no universo infantil por meio de narrativas.

\section{O livro de literatura infantil e o olhar para a ciência}

Não há consenso sobre as origens da literatura infantil. Suzanne Magnanini (2008), professora especialista em literatura italiana, situa tais origens no trabalho de compilação e sistematização de contos de fadas por Gianfrancesco Staparola e Giambattista Basile, ainda no século XVI. Seja qual for o critério que adotemos para traçar um panorama das origens da literatura infantil, é fato que ela sempre teve como uma de suas funções a de educar as crianças. As fábulas de Esopo, conjunto de histórias de cunho moral que remontam à antiguidade grega, são exemplos disso, embora não se possa dizer ao certo que elas se dirigissem especificamente a crianças, conforme aponta o professor de literatura Seth Lerer (2008), da Universidade da Califórnia, em San Diego. Muito do que se vê depois, na literatura dirigida às crianças, tem a mesma perspectiva pedagógica. As professoras Marisa Lajolo e Regina Zilberman (2007) apontam como início da história da literatura infantil a publicação sistemática de contos em sua forma impressa, a partir do século XVII, principalmente em França, onde se destacaram autores como La Fontaine, Fénelon e Perrault.

As histórias produzidas por esses autores, entre outros também da Europa, são aquelas que ficaram conhecidas como contos de fadas. A sistematização em forma escrita de histórias preexistentes respondeu a necessidades socioculturais da época: a instituição familiar passou a assumir crescente importância, e, com isso, tornou-se necessário criar mecanismos para a educação das crianças. $\mathrm{O}$ viés característico dos contos de fadas obedeceu a essas determinações. Embora 
mais complexos que as fábulas de Esopo, recheados de mistérios e de aventuras, os contos de fadas são, fundamentalmente, instrumentos educativos no plano atitudinal, que procuram definir valores morais para as crianças. Tal como nas fábulas, nos contos de fadas é marcante a presença de animais como personagens, embora, na maioria dos casos, os protagonistas sejam humanos. Contudo, como indica o nome pelo qual ficaram conhecidos, os contos de fadas dão destaque a figuras de caráter sobrenatural ou mágico, tais como fadas e bruxas. Lajolo e Zilberman estabelecem também uma relação importante entre a literatura infantil e a escola. A preparação das crianças para o universo letrado pressupõe, evidentemente, o treino da competência leitora.

Os laços entre a literatura e a escola começam desde este ponto: a habilitação da criança para o consumo de obras impressas. Isto aciona um circuito que coloca a literatura, de um lado, como intermediária entre a criança e a sociedade de consumo que se impõe aos poucos; e, de outro, como caudatária da ação da escola, a quem cabe promover e estimular como condição de viabilizar sua própria circulação destinatária (LAJOLO; ZILBERMAN, 2007, p. 18).

Ao tornar-se instrumento de aprendizagem, materializada por meio dos livros impressos, a história infantil ganha maior liberdade temática. Embora se pressuponha que os pequenos devam ler apenas conteúdos edificantes, quando se dispõe de muitas possibilidades de leitura, e sendo importante que a criança treine ao máximo essa habilidade (por estar na fase inicial de aprendizagem), podemos nos dar ao luxo de lhe oferecer histórias para serem lidas pelo mero prazer da leitura. Afinal, o papel de instrumento de aprendizagem da literatura infantil só se concretizará se as crianças lerem as histórias de fato. Essa aparente liberdade, entretanto, nunca chegou a efetivar-se de forma plena. De fato, a literatura infantil é até hoje marcada pelos limites impostos pela escola e todo o processo educativo que a sociedade espera que se reproduza nas crianças. É muito difícil encontrar nela as manifestações mais autênticas e descompromissadas presentes em outros gêneros artísticos, como nos dirigidos ao público adulto. Há exceções, é claro, e uma delas ao menos merece ser mencionada: as histórias em quadrinhos.

$\mathrm{O}$ que nos interessa salientar é que as restrições trazidas pelo sistema educacional ao conteúdo dessas obras não necessariamente as tornam "melhores". Ao fugir de temas delicados e polêmicos e ao limitar a livre expressão artística, a tendência, na verdade, é a de que o conteúdo se torne um tanto insosso na forma e conservador no conteúdo. As mensagens tidas como edificantes podem, muitas vezes, reproduzir ideologias e preconceitos arraigados, mas, em geral, são tacitamente aceitas sem questionamentos. Se acreditamos que um dos papéis da escola é justamente a promoção da reflexão sobre os valores sociais e a promoção de mudanças em relação a estados de coisas essencial- 
mente injustos, o caminho para o uso não apenas do livro infantil, mas de qualquer outro material, é a adoção de uma perspectiva crítica. Isso não significa julgar negativamente os livros, mas encontrar meios de reconhecer os méritos e as limitações de cada obra, de acordo com determinados critérios. Esta é a linha de entendimento das autoras Maria José Palo e Maria Rosa D. Oliveira:

Linguagem carregada de ideologia que permeia cada fala do narrador, cada diálogo das personagens, e tem um destinatário certo: 0 leitor infantil, cujo pensamento se pretende capturar. Não há possibilidade de respostas alternativas nesse processo educativo autoritário que só admite à criança a função de aprendiz passivo frente à voz todo-poderosa do narrador e de seu enfoque da realidade social. Seguindo essa trilha, não é preciso dizer, estão os produtos com menor grau de invenção e de liberdade criativa; perdem em poeticidade $o$ que ganham em imediatismo e em praticidade (PALO; OLIVEIRA, 2006, p. 11).

Um dos principais aspectos dos livros infantis de hoje em dia é o foco na imagem. Tratam-se de livros nos quais a ilustração ganha cada vez mais importância, a ponto de, em muitos casos, a obra ser muito mais pictórica e visual do que propriamente textual. Segundo o estudioso de design Jorge Paiva,

[...] por volta da primeira metade do século $\mathrm{XX}$, os ilustradores passam a explorar cada vez mais o espaço narrativo do livro, seu formato e a relação entre texto e imagem, o que se torna um conjunto narrativo indissociável (2012, p. 23).

Atualmente, cada página de um livro infantil dirigido a crianças de até 10 anos de idade tem uma imagem colorida de grandes proporções, isso quando a imagem não ocupa toda a mancha da página, ficando o texto encaixado em seus espaços vazios. Nelly Coelho, uma das pioneiras na pesquisa em literatura infantil no Brasil, defende que livros desse tipo, "em que a imagem fala tanto quanto a palavra" (COELHO, 2000, p. 196), devem estar presentes no mundo infantil. Assim, talvez hoje seja mais difícil se falar de "literatura" infantil se o conceito de literatura se restringir a uma atividade artística expressa pelo texto verbal.

Mais recentemente, observa-se uma tendência cada vez maior de a imagem se transformar em algo ainda mais chamativo, recorrendo-se a diversos efeitos proporcionados por materiais e técnicas que dão textura e movimento às imagens. Exemplos disso são os livros do tipo pop-up, nos quais, por meio de dobraduras, as imagens literalmente saltam da página, à medida que a criança manipula o livro. Uma análise apurada exige, portanto, considerarmos o livro infantil como um produto que compreende textos verbais articulados a imagens e, muitas vezes, a mais do que isso. Este trabalho está limitado à modalidade composta apenas por imagem e texto, sem efeitos especiais de dobraduras, recortes, etc.

Apesar de, atualmente, os livros infantis apresentarem características que os distinguem de sua origem, alguns elementos permanecem na construção das narrativas e, ao mesmo tempo, favorecem a aproximação com a ciência. 
A professora e pesquisadora em literatura infantil Teresa Colomer (2003), em seu livro A formação do leitor literário, aponta que, quando a literatura infantil se relaciona com práticas educacionais de qualquer tipo, pretende estabelecer significado entre a criança que lê e a obra, partindo de sistemas de identificação criados por experiências pessoais e "literárias". Segundo a autora, esse estabelecimento oferece ao leitor "uma maneira articulada de reconstruir a realidade, de gozar dela esteticamente, de explorar os pontos de vista próprios através da apresentação de outras alternativas" (COLOMER, 2003, p. 133). Para nortear nossas discussões sobre a aproximação existente, podemos apontar dois elementos que merecem destaque: a predominância de narrativas construídas com relações entre personagens animais que remetem a conteúdos científicos, objetivamente ou não; e o diálogo possível entre a realidade e a fantasia como pertencente, ao mesmo tempo, ao universo científico e ao infantil.

As relações entre os personagens animais e entre animais e humanos que ainda estão presentes nas narrativas infantis contemporâneas são elementos que permitem a abordagem de temas da ciência sob diferentes perspectivas. Em um levantamento realizado por Linsingen (2008), o significado atribuído aos animais na literatura infantil é determinante para a construção das narrativas com esses personagens, por configurar diretamente uma unidade de identificação com a criança e pelo signifi- cado atribuído a eles, acerca de inúmeros aspectos, dentre os quais, destacam-se os estereótipos construídos, a boa relação com as crianças e suas simbologias.

Para o pesquisador Steve Baker (2001), a maneira como os animais são representados na mídia expressa comportamentos sociais da vida humana, evidenciando apenas as relações reais da natureza consideradas necessárias para a compreensão do valor atribuído. Dessa forma, mesmo os aspectos sociopolíticos mais diretamente ligados às relações humanas - representados nos personagens animais antropomorfizados - trazem igualmente temas pertinentes à educação científica nos anos iniciais do ensino fundamental, integrando questões como preconceito, relações reprodutivas e de gênero, diversidade, entre outras, que, se tiverem fundamento social, também podem e, segundo diversos autores (BRASIL, 1997; CHARPAK, 1996; CACHAPUZ et al., 2005; KRASILCHIK; MARANDINO, 2004; BIZZO, 2009), devem estar presentes no ensino de ciências, sobretudo nos anos iniciais, nos quais os conteúdos de ciências da natureza não se desvinculam dos demais, como a alfabetização, as ciências sociais, a linguagem, as artes e a matemática.

Essencial para os livros infantis também é a fantasia como constituinte das histórias, que, por sua vez, caminha constantemente com a realidade e tem por objetivo principal buscar o envolvimento do leitor. Ao discutir a relação das crianças com as histórias infantis, Guelfi aponta que "embora essas histórias se- 
jam imaginárias, não são falsas pois se referem a outra espécie de realidade - a do inconsciente [...]" (1996, p. 144). Operando entre esses dois mundos - fantasia e realidade-, as narrativas direcionadas para as crianças encontram na ciência o que a própria ciência, enquanto construção epistemológica, compreende:

Se o real imediato é um simples pretexto de pensamento científico e não já um objeto de conhecimento, será necessário passar do como da descrição ao comentário teórico. Essa explicação prolixa espanta o filósofo que desejaria sempre que uma explicação se limitasse a desdobrar o complexo, a mostrar o simples no composto. Ora, o pensamento científico autêntico é metafisicamente indutivo; como mostraremos em várias oportunidades, ele lê o complexo no simples, revela a lei a propósito do facto, a regra a propósito do exemplo (BACHELARD, 2000, p. 12).

É nessa dimensão que Bachelard (2000) sugere um elo de complementaridade entre a ciência e o imaginário enquanto uma forma de representação. Assim, o estranhamento e a problematização se estabelecem como conhecimentos anteriores e originários do pensamento científico, na medida em que a fantasia não apenas conjectura 0 real, mas também atua como ponto de partida para pensar e refletir sobre ele em diferentes perspectivas. Conhecer um objeto é agir sobre ele nos níveis possíveis estabelecidos na experiência do sujeito, o que, ao mesmo tempo, permite olhar a literatura para além dos polos do pedagogismo e da arte.

\section{O passeio de Rosinha}

A obra $O$ passeio de Rosinha (HUTCHINS, 2004) - do original em inglês Rosie's walk -foi escolhida por atender a requisitos voltados para crianças em fase de alfabetização. A autora Pat Hutchins nasceu na Inglaterra e escreveu a obra em 1968, porém a tradução só foi lançada no Brasil em 2004. Trata-se de um livro bastante utilizado em atividades de diferentes áreas, como ciências, artes e língua materna (SMOLKIN, 1999; HARRISON, 2001; GLEDHILL, 2003). Existe também uma adaptação da história em vídeo (DEITCH, 1970).

A história narra o passeio de uma galinha chamada Rosinha, do início da tarde até a hora do jantar. Ela passeia por diversos locais da fazenda, como em volta do lago, em cima do monte de capim, em frente ao moinho, atravessando a cerca, etc., enquanto uma raposa a persegue com a intenção de pegá-la. A raposa tenta fazer o mesmo caminho que a galinha para capturá-la, porém sempre encontra alguma dificuldade e não consegue alcançá-la. Por fim, Rosinha volta para casa sem sequer notar a presença da raposa.

O livro tem pouco texto, apenas uma frase simples a cada duas páginas. A fonte utilizada é a denominada letra de imprensa minúscula, embora os alunos em fase de alfabetização conheçam melhor as letras maiúsculas. As imagens ocupam todo o espaço da página, são muito coloridas e bem ilustradas, sua sequência, por 
si só, possibilita a narração da história (Figura 1). Essa característica é importante para os alunos que ainda não estão completamente alfabetizados. A imagem da capa do livro apresenta o local em que Rosinha vai passear e também informa sobre a existência de uma raposa. Cada conjunto de páginas mostra um local da fazenda e sua sequência é interligada, como demonstrado na contracapa do livro, que ilustra toda a paisagem da fazenda em que se passa a narrativa.

Ao ler o livro com foco apenas no texto, é possível observar que ele narra exclusivamente o passeio da galinha: "A galinha Rosinha foi passear à tardinha / Andou pelo quintal / Caminhou em volta do lago / Passou por cima do monte de capim / Em frente ao moinho / Atravessou a cerca / Passou por baixo das colmeias / E voltou bem na hora do jantar" (HUTCHINS, 2004). Paralelamente, as ilustrações complementam a história, demonstrando a presença, a intenção e o fracasso da raposa. Essa estratégia, como descrito na própria contracapa do livro, demonstra a importância atribuída ao uso de imagens para despertar o interesse pelo livro e pela leitura em crianças em fase de alfabetização, além de propiciar o desenvolvimento das habilidades básicas, já mencionadas, necessárias a esse processo.

Figura 1 - Uma das páginas ilustradas de O passeio de Rosinha

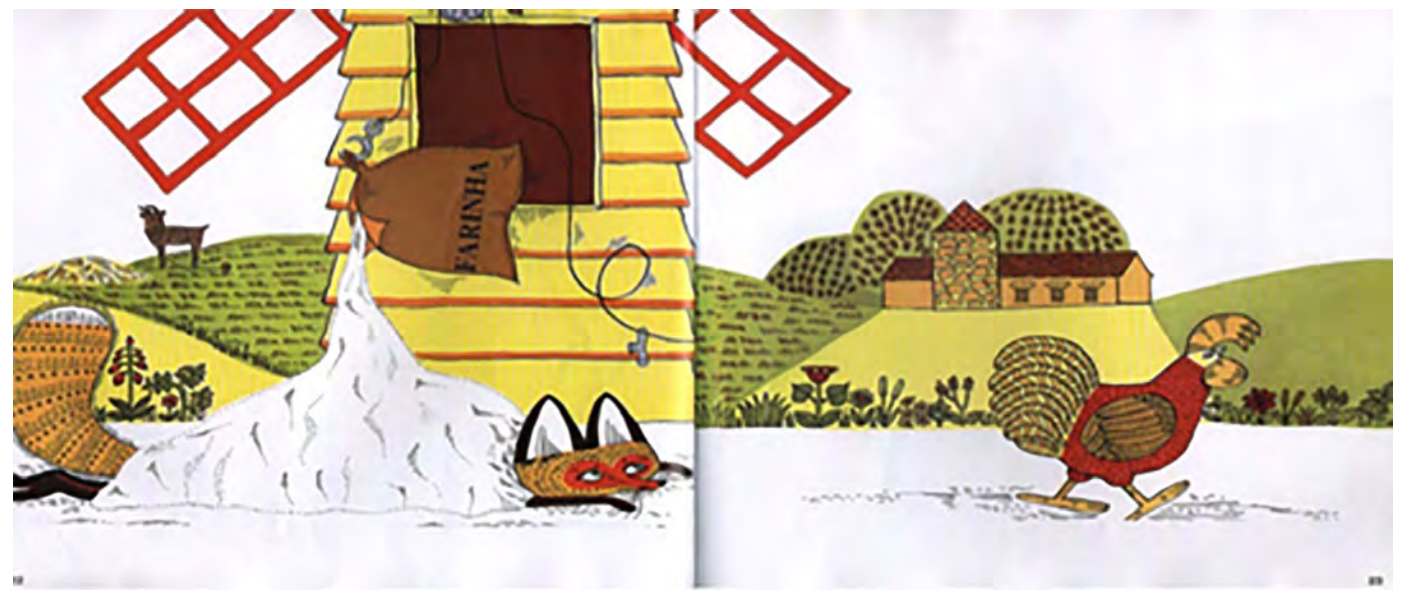

Fonte: Hutchins (2004).

\section{Caminhos de análise}

A questão fundamental desta proposta é aproveitar a atividade de leitura das crianças para explorar temas de ciências.
Para isso, é importante ter em mente que qualquer atividade com estudantes nessa faixa etária deve procurar articular diversas frentes de aprendizado de conhecimentos, habilidades e atitudes, em 
âmbitos variados, conforme apontam os diversos pesquisadores do tema. Entendemos que um passo importante nesse processo é a análise dos livros, voltada não só para a identificação de possibilidades, mas também de eventuais problemas que uma visão crítica possa revelar, que podem ser incorporados à prática didática. É importante ressaltar que essa visão crítica não significa rejeitar a obra, conforme apontado por diversos autores, mas, sim, encontrar, nela, desafios e questões a serem abordados nas atividades com as crianças. O caminho que propomos faz uso de conceitos da semiótica de A. J. Greimas (GREIMAS, 1973; GREIMAS; COURTÉS, 2008), linguista lituano da segunda metade do século XX, cujo trabalho deu origem à extensa e produtiva área de pesquisa sobre linguagem e significação. Tal linha semiótica tem como pressuposto básico que qualquer enunciado analisável em termos de uma transformação de estado de um sujeito em relação a um objeto constitui uma narrativa (GREIMAS; COURTÉS, 2008, p. 294) e pode ser analisado por meio do chamado percurso gerativo do sentido (BARROS, 2005, p. 13), que considera o texto a partir de três níveis: o discursivo, o narrativo e o fundamental. Seguindo essa linha, procuramos evidenciar aspectos diretamente relacionados ao conteúdo de ciências implícito na história analisada, nem sempre percebidos em uma primeira leitura.

\section{Nível discursivo: espaço, tempo e pessoa}

Uma caracterização do nível discursivo é trazida pela semioticista Diana Barros:

O sujeito da enunciação faz uma série de "escolhas", de pessoa, de tempo, de espaço, de figuras, e 'conta' ou passa a narrativa, transformando-a em discurso. O discurso nada mais é, portanto, que a narrativa "enriquecida" por todas essas opções do sujeito da enunciação (2005, p. 53).

Na chamada sintaxe narrativa, analisamos a configuração do processo de enunciação pelo posicionamento do enunciador. Na semântica, que será o foco de nossa análise, três elementos fundamentais do discurso - o espaço, o tempo e os atores - são colocados em termos de relações entre figuras e temas.

\section{Pessoa}

Pessoas, ou atores, são todas as entidades individualizadas, humanas ou não, animadas ou não, que operam ou sofrem ações (transformações em relação a objetos) ao longo da narrativa (GREIMAS; COURTÉS, 2008, p. 14). Se considerarmos apenas o texto escrito do livro em análise, o único ator da história é a galinha. O texto passa a ideia de um animal cujo comportamento é, de certa forma, humano, que gosta de passear e está dando uma voltinha antes do jantar. O espaço é um sítio ou fazenda. Quando analisamos as ilustrações, porém, vemos que é necessário considerar outro ator - um animal presente em toda a narra- 
tiva e que parece perseguir Rosinha: a raposa. Há outros animais também, mas eles não parecem participar diretamente da história.

Uma primeira observação é sobre a forma escolhida para retratar a galinha e a raposa na história (não operam transformações). Podemos considerar dois aspectos: a aparência visual e o comportamento, componentes do que Greimas e Courtés (2008, p. 14) denominam valores pragmáticos objetivos, constituindo propriedades intrínsecas dos sujeitos. Diversos aspectos podem ser considerados, como as cores, os elementos presentes e sua disposição, bem como as proporções. Vemos que Rosinha é vermelha e tem cauda de longas penas, grande crista vermelha, asas destacadas com cor diferente do que o resto do corpo, a cabeça e a cauda são amareladas, também em cor diferente. Em relação ao comportamento, Rosinha tem certo ar de indiferença: não parece feliz, nem triste, e seu olhar não se desvia, está sempre fixo em frente. Ao longo do trajeto, caminha incessantemente da esquerda para a direita do quadro, sem nenhum sobressalto.

Uma maneira de evidenciarmos a construção ficcional para as crianças é realizar comparações dessas características da personagem com as galinhas reais. Muitas crianças observariam que as galinhas verdadeiras têm aparência diferente daquela representada e também um comportamento distinto: muitas vezes estão ciscando e têm um caminhar mais aleatório do que o de Rosinha; poderiam também lembrar que, quando ameaçadas, em geral, as galinhas saem correndo e cacarejando, agitando as asas.

Já em relação à raposa, talvez o primeiro ponto a ser levantado é saber se as crianças identificam o animal, que é um mamífero raro no Brasil. Nesse aspecto, a influência da mídia é evidenciada, pois verificamos, em sala de aula, que muitas crianças identificam corretamente $o$ animal, possivelmente por o terem visto na televisão.

\section{O espaço}

Considerando a questão do espaço, a história tem como pano de fundo um sítio ou fazenda. Ele é representado como um espaço harmônico, seguro e bonito. Não há nada que induza ideias de medo, perigo, maldade ou coisas do gênero. A paisagem tranquila é composta por diversos elementos. Como Rosinha vai passeando, diversos locais se sucedem, todos eles integrantes da fazenda. A galinha passa perto de várias edificações - casas, celeiros, moinho -, e diversos elementos são representados (carrinho, rastelo, colmeia). Também há plantações, um lago e uma vegetação de fundo. Rosinha parece não interagir com esse ambiente. O texto do livro é claramente voltado para a apresentação de advérbios de lugar, são seis advérbios no original inglês: across, around, over, past, through e under; e a tradução em português recorre aos termos: "em volta", "por baixo", "por cima", em alguns casos, 
eliminou-se completamente os advérbios, como em "atravessou a cerca". Esses mecanismos linguísticos ajudam a situar a personagem no espaço, colocando-a em movimentos e posições relativos aos elementos do cenário.

Observamos que não há interação da galinha com esses elementos, mas isso ocorre ativamente com a raposa, de modo a atrapalhar sua perseguição pela galinha. Em relação ao espaço, podemos também examinar a localização geográfica do espaço retratado: esse tipo de fazenda está localizado em que parte de nosso planeta? Existem fazendas assim em nosso país, estado ou cidade? Podemos perguntar às crianças se elas já foram a uma fazenda e que diferenças e semelhanças observaram em relação ao que é retratado no livro. Também podemos pedir que opinem a respeito do local em que uma fazenda como essa poderia existir.

\section{O tempo}

A análise do tempo na narrativa pode considerar dois aspectos. O primeiro deles é a localização histórica da narrativa. Podemos perguntar se essa história se passa no passado, no presente ou no futuro, partindo de tudo o que já analisamos e obtivemos como resposta em relação ao espaço. Embora acreditemos que não seja exatamente o caso, poderíamos concluir, por exemplo, que esse tipo de fazenda não existe mais. Isso porque sabemos que a criação de animais como galinhas para comercialização em massa não se dá, atualmente, como a história retrata. De qualquer modo, poderíamos supor que se tratasse de uma criação para consumo próprio do fazendeiro. Muitas vezes, é possível estabelecer relações conotativas entre diferentes épocas, com ideias implícitas como: "no passado tudo era melhor" ou "antigamente as coisas eram difíceis, perigosas, etc.”. Isso vale tanto para o tempo quanto para o espaço, e sempre pode ser discutido com as crianças.

Outro aspecto temporal está ligado à duração e aos intervalos de tempo retratados. Podemos chamar a atenção das crianças para esse ponto, questionando-as sobre a duração dos eventos retratados (um minuto, uma hora, um dia, um mês, um ano) e como isso aparece na história. Podemos perguntar se a forma como o tempo é retratado na história equivale ao tempo real, percebido em uma situação como essa. Também há o tempo de leitura, que pode ser mais curto ou mais longo do que os eventos retratados. No caso da história analisada, Rosinha vai passear à tardinha e chega na hora do jantar, o que permite estabelecer um espaço de tempo da ordem de hora ou horas. As crianças podem julgar, por exemplo, que Rosinha fez pouca coisa para esse tempo todo, mas, para isso, elas têm de identificar essas marcações de tempo no texto da história, como acabamos de apontar. 


\section{Nível narrativo}

Outro aspecto fundamental a ser considerado é a história em si, seu percurso, do início ao fim, e o papel dos vários elementos dentro dessa lógica. Toda história possui um sujeito, alguém que está em busca de algo, mesmo que não explicitamente. Esse algo, que pode ser representado por um objeto físico ou por outro elemento concreto, deve ser entendido, de forma mais abstrata, como um valor a ser obtido. A narrativa do livro pode ser analisada sob dois pontos de vista: o da galinha Rosinha e o da raposa.

Do ponto de vista da galinha, o objetivo valorizado é o próprio passeio, um tempo livre, um tempo sem preocupações. Existem os perigos - representados, sobretudo, pela raposa -, mas parece que a galinha está tão protegida por seu ambiente, tão adaptada a ele, que nada de mal pode lhe acontecer. Não é difícil associar a figura da galinha à representação de uma dona de casa, de uma mãe. Nos livros infantis, é bastante comum a galinha ser representada como um ser doméstico e ingênuo, cuja função é basicamente a de cuidar do lar e das crianças (ou dos ovos). O que a história apresenta implicitamente é uma vida pacata, na qual o principal valor é o tempo livre, o passeio pela fazenda.

A raposa, por sua vez, tem como valor a galinha, entendida como presa, necessária, supostamente, para sua alimentação, embora isso possa não ficar bem claro para as crianças em uma primeira leitura. Todavia, diversos obstáculos se interpõem à busca da raposa. Esses obstáculos são basicamente os elementos da fazenda, a colmeia, o carrinho, o moinho, o lago, o monte de feno. Todos eles representam contratempos para a raposa e acabam contribuindo para o insucesso de sua busca, finalizada quando ela é perseguida por um enxame. A raposa, supostamente um animal esperto, ao menos nas representações ficcionais, é apresentada como um ser mais ágil do que a galinha, o que não é necessariamente verdade - basta pensar que, numa situação real, dificilmente uma galinha ficaria passiva e indiferente ao sofrer ameaça de captura.

Ao final da história, após a raposa não conseguir obter seu objeto de valor, o passeio da galinha termina de volta a uma pequena estrutura, que parece ser um galinheiro, com a frase: "e voltou bem na hora do jantar", o que pode remeter a uma ambiguidade quanto ao valor da galinha enquanto alimento do humano.

Nesse sentido, destaca-se a importância de considerar a narrativa do ponto de vista da busca de um sujeito por um valor e de refletir não somente a respeito dos aspectos superficiais do texto, mas também sobre possíveis interpretações figurativas. É importante que essas interpretações, que necessariamente possuem certo grau de subjetividade, sejam verificadas em sua consistência. Isso pode ser feito seja averiguando a coerência dos elementos da história como um todo, seja tomando como base referências externas. 


\section{Contrariedades}

Toda narrativa trabalha com diversas contrariedades. Alto e baixo, claro e escuro, natural e artificial, feminino e masculino, moderno e antigo, e assim por diante. Quando mapeamos as contrariedades de uma história e vemos como elas estão vinculadas umas às outras, podemos entender certos aspectos que, muitas vezes, não são fáceis de perceber inicialmente. A análise de oposições nessa história pode partir da oposição mais óbvia, raposa e galinha, que remete a diversas outras: selvagem e doméstico, floresta e fazenda, predador e presa, etc. Podemos listar esses termos conforme o Quadro 1:

Quadro 1 - Valores contrários

\begin{tabular}{|l|l|}
\hline \multicolumn{1}{|c|}{ Valor positivo } & \multicolumn{1}{c|}{ Valor negativo } \\
\hline Galinha & Raposa \\
\hline Fazenda & Floresta \\
\hline Doméstico & Selvagem \\
\hline Presa & Predador \\
\hline
\end{tabular}

Fonte: elaboração dos autores.

A função dessa listagem é evidenciar determinadas tendências ideológicas, passíveis de questionamento, veiculadas no texto. Será que a galinha é mesmo boazinha e a raposa má? Por que a raposa é má? Porque ela come galinhas? Mas nós também não comemos galinhas? Então, somos maus? E se a raposa não comer a galinha, o que acontecerá a ela? Os animais que moram na fazenda são bons e os da floresta são maus? Isso é verdade? Todos esses questionamentos são possibilidades que surgem a partir da análise das oposições presentes na história e podem transformar-se, imediatamente, em perguntas a serem levantadas nas atividades em sala de aula. É possível encontrar muitas outras oposições, e algumas delas poderão auxiliar o professor a planejar formas interessantes de explorar o conteúdo da obra.

\section{Atividades exemplares}

As atividades a seguir foram aplicadas em uma escola da rede municipal de Guarulhos, no estado de São Paulo, em duas turmas diferentes, por uma professora efetiva da rede desde 2008. A primeira delas foi aplicada, em 2010, em uma turma de $1^{\circ}$ ano do ensino fundamental, com alunos com idades entre 5 e 6 anos. Em 2011, a segunda atividade foi aplicada em uma turma distinta, em um $2^{\circ}$ ano do ensino fundamental, com alunos com idades entre 6 e 7 anos. $\mathrm{O}$ objetivo dessas aplicações foi situar e balizar as formulações analíticas em função de contextos concretos de ensino, para verificar em que medida os instrumentos teóricos empregados encontram correspondência em situações de sala de aula, além de planejar, dirigir e interpretar as atividades didáticas ocorridas. Os dados foram coletados por meio de anotações diárias, escritas pela professora durante e após as atividades. 
Atividade 1: "A raposa vai te pegar!"

Na primeira turma de alunos, com idades entre 5 e 6 anos, a maior parte das crianças estava em fase inicial de alfabetização. Na primeira atividade, os alunos foram divididos em grupos. Inicialmente, cada grupo folheou o livro, depois, sem intervenção da professora, os alunos contaram a história uns para os outros. Nos grupos em que não havia nenhuma criança alfabetizada, os alunos acompanharam a história apenas pela sequência das imagens. Foi solicitado aos alunos que narrassem a história contada no livro.

\section{Os alunos narram a história}

Ao compreender o enredo da história, os alunos demonstravam preocupação com a galinha, ficavam agitados a cada tentativa da raposa de avançar sobre a presa e ainda mais interessados em continuar a história. Uma das crianças chegou a dizer, espontaneamente: "Cuidado galinha, a raposa vai te pegar!". Essa fala demonstrou que os alunos interagiam com a história para tentar solucionar o problema existente e queriam avisar a galinha de que estava correndo perigo.

Enquanto narrava a história, um dos alunos perguntou à professora se em determinada frase estava escrito que a raposa tentava pegar a galinha, o que sabemos que não ocorre no texto. Mas a frase a que o aluno se referiu estava nas primeiras páginas do livro, nas quais as imagens tornam evidente a intenção da raposa. Nesse primeiro comentário, nota-se que os alunos compreendem que deve haver uma relação entre texto e imagem.

Observamos que, enquanto um dos alunos narrava o caminho percorrido pela galinha, os outros apontavam para elementos secundários presentes na ilustração, como os animais que faziam parte do contexto da história e as características próprias de um ambiente rural, muitas árvores e plantações, entre outros aspectos.

\section{A torcida e o desfecho}

Percebemos como a história despertou a curiosidade das crianças, pois, em diversos grupos, antes de a história terminar, os alunos tentavam imaginar o que aconteceria. Em determinado grupo, dois alunos acharam que a galinha seria morta. Outros dois defenderam a ideia de que ela permaneceria viva. Alguns alunos se identificaram com o papel da galinha e argumentaram que ela seria a mais inteligente por não ter sido pega. Ao mesmo tempo, outras crianças identificaram-se com a raposa, com sua esperteza e sua rapidez, além de destacarem a beleza do animal. Essas afirmações das crianças, feitas aleatoriamente, foram posteriormente reafirmadas na proposta de um desenho da história, quando muitas desenharam o animal com o qual se identificaram. 
Há um vilão na história? As relações entre os animais

Em um momento seguinte, a professora fez perguntas previamente preparadas a respeito de temas que ainda não haviam sido trazidos espontaneamente ou aprofundados pelos alunos. Essas questões abordaram, basicamente, o hábitat natural dos animais e seus hábitos alimentares. Uma vez que os alunos já haviam mencionado os diversos elementos componentes da história e demonstrado clareza quanto ao local em que esses animais vivem, percebe-se que os alunos tinham informações e ideias corretas sobre o assunto. Entretanto, ao serem questionados sobre a intenção da raposa de comer a galinha, houve uma divisão de opiniões em que a questão da ética se sobressaiu.

Duas crianças atribuíram valores morais à situação, apontando a raposa como má pelo fato de querer comer a presa. A situação foi, então, problematizada, para que esses alunos pudessem pensar nos motivos para a raposa ter essa atitude. Nesse momento, a professora perguntou: "Mas, se a raposa não comer a galinha, o que ela vai comer?". Então, um dos participantes do grupo comentou que a raposa precisava comer outros animais. Os demais demonstraram compreender a razão da atitude da raposa e fizeram até outra problematização: "É mesmo, se a raposa não comer ela pode morrer". As crianças identificaram a história como uma situação real porque ela apresenta animais num ambiente em que é possí- vel sobreviver - a fazenda. Além disso, comentaram sobre histórias pessoais que se passaram em fazendas e sítios, também com a presença de animais representados na história.

\section{Atividade 2: "O passeio da raposa"}

$\mathrm{Na}$ aplicação com a segunda turma de alunos, consideramos as diversas possibilidades de interação das personagens da história com o meio ambiente, a relação presa-predador e as características do local em que se desenvolve a narração, que não faz parte do cotidiano dos alunos que moram na região urbana em que $o$ trabalho foi desenvolvido. Além disso, focamos em elementos que permitissem ampliar o conhecimento dos alunos, como as imagens do moinho, do lago e da colmeia, e a presença de animais desconhecidos por muitos alunos, como o bode e a marmota.

\section{O que será da galinha?}

Ao perceber o enredo da história, muitos alunos demonstraram preocupação com a galinha, e a cada vez que a raposa tentava avançar sobre a presa, os alunos ficavam agitados e ainda mais interessados em continuar a história. Tal como na primeira turma, os alunos ainda não alfabetizados demonstraram interesse em saber o que estava escrito em algumas partes do livro, em geral nas páginas que ilustravam a raposa muito próxima à sua presa. Vários grupos expressaram sua curiosidade, pois antes mesmo de terminar a história, 
verbalizavam desfechos imaginados. No final, a professora fez a leitura do texto em voz alta para a classe e muitos alunos demonstraram sua preocupação quanto à sobrevivência da galinha.

\section{O espaço do sítio}

Os alunos expressaram conhecimentos prévios em relação ao espaço em que a história se passava, identificando os ambientes como a plantação e o lago. Suas falas revelaram que sabiam como é uma fazenda ou sítio. Este momento caracterizou-se como interligação do processo de construção da escrita com a sequência narrativa. Foi possível observar também a organização dos grupos e o interesse de alguns alunos em ajudar os colegas. Foi realizada também uma etapa de encontrar e circular no texto as palavras que designavam os locais por onde a galinha passou. Todos os grupos se empenharam. Alguns dividiram as tarefas de modo que cada integrante do grupo circulasse uma palavra. Caso algum aluno não conseguisse ler, os outros o auxiliavam na leitura para que ele identificasse a palavra procurada. Ao registrar na lousa os locais circulados pelos alunos, apenas um elemento não era do conhecimento de todos: o moinho. Embora alguns já o tivessem visto em desenhos ou em filmes, não conseguiam explicar sua função.

\section{Os conhecimentos dos animais do sítio}

Além de elementos característicos de um ambiente rural, os alunos apontavam a presença de animais secundários. Embora alguns animais fossem menos conhecidos, como o bode e a marmota, alguns alunos que os conheciam tomaram a iniciativa de dizer aos colegas quais eram os nomes deles e onde os tinham visto - na televisão ou até mesmo no zoológico. A professora pediu então à classe o nome de cada animal retratado no livro. Os alunos folheavam o livro identificando os animais presentes em cada conjunto de imagens e, logo após, escrevendo os nomes em seus respectivos cadernos. Os integrantes dos grupos ajudavam os colegas que sentiam mais dificuldade, repetindo o nome do animal ou até mesmo lembrando as letras correspondentes aos sons da palavra. Alguns alunos demonstraram interesse em escrever os nomes na lousa. Assim, o restante da sala pôde observar a escrita na lousa e compará-la com sua escrita pessoal. Houve alunos que questionaram o uso de determinadas grafias e, em seguida, propuseram alterações nas palavras escritas na lousa e no caderno.

Os alunos identificaram os seguintes animais: galinha, raposa, sapo, passarinho, bode, rato, castor e abelha. Eles não conheciam o nome marmota, mas o castor, que é um animal fisicamente semelhante, era de conhecimento geral. Como não podemos afirmar categoricamente que aquele animal é um castor ou 
uma marmota, optamos por identificá-lo como castor.

\section{Desenhando e recontando a história}

A etapa final da atividade foi recontar a história utilizando figuras desenhadas pelos próprios alunos, que foram enriquecidas pelo conhecimento que muitos detinham sobre $o$ ambiente e também pela compreensão que demonstraram ter sobre a necessidade de a raposa se alimentar, como ocorreu na atividade anterior. As crianças demonstraram interesse em participar da atividade e até certa euforia para recontar a história. Foi dessa forma, também, que realizaram a atividade de fazer um desenho sobre o livro, demonstrando interesse em representar aquilo que mais lhes chamou a atenção, seja pela ilustração do livro, seja pela situação, engraçada ou perigosa, em que as personagens se encontravam.

A reescrita da história, narrando " $\mathrm{O}$ passeio da raposa” - título escolhido pelos alunos -, contribuiu em diversos aspectos. Em primeiro lugar porque os alunos tiveram de criar argumentos para justificar o interesse da raposa em ir atrás de Rosinha e verificar a possibilidade de haver outra interpretação da mesma história. Além disso, a atividade contribuiu para a fase de alfabetização em que os alunos se encontravam. $\mathrm{O}$ texto foi copiado no caderno de cada aluno. Durante os debates envolvidos nessas etapas, foi possível reservar momentos para os alunos escutarem as dúvidas dos outros colegas e até mesmo tentarem solucioná-las, segundo seus conhecimentos.

\section{Análise do desenvolvimento das atividades}

Chamar a atenção das crianças para os detalhes é favorecer a habilidade de observação. A relação estabelecida com os elementos estéticos do livro infantil aponta para interpretações variadas e que vão além do texto escrito. São esses apontamentos que possibilitam que as crianças falem sobre suas identificações com a história, suas interpretações sobre as conotações dos personagens em suas relações naturais e sobre as previsões diante dos desfechos possíveis, o que acontece antes mesmo de a professora propor discussões ou questionamentos a respeito das temáticas científicas que se direcionam a isso.

As interpretações trazem concepções da ciência sobre os animais identificados, que podem ser aprofundados com a mediação do professor. Vale a pena considerar, ou pedir que elas mesmas opinem, sobre o porquê das diferenças entre animais reais e ilustrados. Por que será que o desenhista fez as modificações que observamos? Claro que não existe resposta "correta" nesse caso e, possivelmente, nem mesmo o próprio desenhista tem consciência desses porquês. De qualquer maneira, essa prática favorece o desenvolvimento de habilida- 
des de interpretação e de análise crítica por parte das crianças.

Com isso, também encaminhamos algumas das questões sobre os animais. Observamos, na análise realizada sobre a obra, que a galinha é representada na história como um animal passivo diante das situações do meio, diferente do seu comportamento natural, o que pode contribuir para a construção das concepções da relação que as crianças estabelecem com esse animal, essencialmente quanto a refletir sobre seu valor comercial e econômico. Vale a pena, para complementar essa análise de conteúdo, voltar a atenção para todos os animais presentes na história, o que pode proporcionar outro momento de atividade com as crianças.

Nas imagens, além da galinha e da raposa, há: borboletas; sapos; pássaro; ratos; bode; marmota e abelhas. Nem todos os animais são fáceis de identificar e, certamente, haverá dúvidas em relação à marmota, por exemplo. Um animal similar é o castor, que vive apenas em ambientes aquáticos (à beira de riachos), os quais não são retratados na história. Em relação ao pássaro, é possível que o desenhista tenha se inspirado em uma espécie específica, presente no ambiente que ele procurou retratar. Outros animais, como sapos, borboletas e abelhas, também são divididos em inúmeras espécies, que, em geral, as pessoas não especificam ao identificar o animal. De um modo ou de outro, é bastante interessante chamar a atenção para todos os animais e considerar a possibilidade de, ao menos, propor que as crianças os classifiquem de forma genérica, com perguntas do tipo: que animais vocês julgam parecidos? Por quê? Apenas nessa história, há exemplos de três mamíferos (raposa, marmota e bode), duas aves (galinha e pássaro), um anfíbio (sapo) e dois insetos (borboleta e abelha).

Se o professor dispuser de livros ilustrados com fotos de animais (enciclopédias, guias ilustrados, etc.), poderá realizar uma atividade que busque não só identificar os animais da história, mas também compará-los a outros similares. Outra alternativa é o uso de imagens obtidas na internet, que poderão ser impressas ou projetadas, mas isso depende muito dos recursos disponíveis na escola. Para crianças em fase inicial de alfabetização, em uma escola que disponha de computadores (ou ao menos de um computador e de um projetor), uma ideia interessante é utilizar sites de busca de imagens. Se o professor estiver familiarizado com esse recurso, poderá usar um dos mais conhecidos (Google, Yahoo ou Bing) e, na página correspondente de busca de imagens, solicitar que as crianças digitem o nome de um animal no campo de busca. Sapo, pássaro e borboleta são exemplos interessantes, pela variedade de imagens disponíveis. As crianças podem ser estimuladas a procurar imagens que se assemelhem às do livro e a distinguir fotos de desenhos realistas e desenhos caricaturais.

Uma sugestão de abordagem a partir dessa constatação seria pedir aos alunos que narrassem a história do ponto de 
vista da raposa. É uma história mais complexa, pois ela passa por diversas situações. Ela não anda simplesmente por cima do monte de capim (na verdade, feno), ela acaba por entrar no meio da pilha e também mergulha na água do lago, é coberta pela farinha, e assim por diante. Podemos questionar as crianças a respeito de cada um desses espaços, o que eles representam e qual sua função na fazenda. Também é possível considerar a relação entre os animais e o ambiente. Há animais que são da fazenda, fazem parte de criações. A galinha, o bode e as abelhas estão ali por razões econômicas, por fornecerem determinados recursos, como ovos, leite e mel. Tudo isso pode ser levantado e questionado. Também há animais que estão nesse local a contragosto do fazendeiro, que preferiria que eles se mantivessem afastados, como é o caso da raposa e da marmota. Podemos questionar as crianças sobre o porquê de esses animais irem até a fazenda. $\mathrm{E}$ se a fazenda não é, de fato, sua morada original, qual seria essa morada, e por que razão eles não permanecem lá? Essas perguntas levam a questionamentos sobre o meio ambiente.

Como vimos na análise, os elementos do espaço interagem com a raposa de forma negativa, sempre que ela tenta capturar a galinha, os objetos do espaço a atrapalham, contribuindo para que as crianças percebam os dois animais principais e sua relação alimentar sob duas diferentes conotações, de bom e de mal, visto que há uma espécie de punição para a atitude da raposa. Há também animais que não fazem parte de criações, mas habitam normalmente a fazenda ou fazem uso de seu espaço, como os pássaros, as borboletas e os sapos, que, a princípio, não são indesejados pelo proprietário rural. Podemos perguntar às crianças se esses animais têm alguma utilidade, do ponto de vista do fazendeiro. É bom lembrar que sapos e pássaros são predadores de insetos e que borboletas e pássaros são essenciais na polinização.

Vale a pena questionar as crianças a respeito de diversos desses pontos. $O$ fato de a fazenda não ser o ambiente natural da raposa, o que a faz se defrontar com diversas situações inesperadas, pode ser uma linha argumentativa, mas é aconselhável deixar que as crianças pensem de forma crítica sobre o assunto e que imaginem alternativas.

Algumas perguntas que podem gerar bastante discussão são: por que a galinha mora na fazenda e a raposa não? Será que a galinha foi morar na fazenda por sua própria vontade? Qual é a função dela ali? E a raposa, por que vai buscar alimentos na fazenda? Ela não tem o que comer em seu ambiente natural? Por quê? Veja que essas questões remetem ao uso dos recursos naturais pelo homem e ao impacto que isso provoca na natureza, gerando importantes pontos de discussão com as crianças. As respostas às questões colocadas pelo professor, ou pelos próprios alunos, permitem que verifiquemos se eles estão compreendendo os assuntos de ciências apresentados. 
Esse processo contribui, também, para o desenvolvimento do raciocínio e para a organização das ideias ao explicar as respostas dadas ou apresentar dúvidas.

Durante as atividades, as crianças perceberam a narrativa, ou partes dela, como um problema a ser resolvido. Entendemos que a investigação ou a resolução de um problema pode funcionar como um ponto de partida para a discussão de temáticas científicas que possam estar relacionadas com as histórias, além de estimular as crianças a elaborar hipóteses, considerar distintas possibilidades e comprová-las.

Compreender novos conceitos e relacioná-los à realidade é uma tarefa muito importante para os alunos. Como o conteúdo ou o assunto só serão valorizados pelo aluno se fizerem sentido para ele, é importante estimular esse processo de reflexão a partir de, por exemplo, diálogos com o outro. Esse processo é necessário para que os alunos possam não só expressar suas próprias dúvidas, mas também compreender as dos colegas, levantar hipóteses, elaborar respostas e relacioná-las com as explicações fornecidas pelo professor, ampliando, assim, seus conhecimentos. O processo que realizamos com a galinha pode ser igualmente estendido para a raposa, também com o uso de fotografias de animais reais. Vale a pena procurar imagens que se assemelhem à raposa retratada na história, porque é possível que o desenhista tenha se inspirado em uma espécie existente. Mesmo assim, veremos que as diferenças são muito grandes entre o desenho e a fotografia, $\mathrm{e}$ estimular as crianças a verificar e questionar semelhanças e diferenças é sempre uma atividade bastante produtiva.

\section{Considerações finais}

A utilização de livros infantis para abordar conceitos de uma determinada área do conhecimento tem demonstrado contribuir significativamente para o desenvolvimento de habilidades cognitivas e afetivas durante o processo inicial de escolarização, conforme os apontamentos realizados inicialmente. Tal evidência garante ainda mais relevância e espaço no processo educacional, dada a sua importância histórica.

Os resultados observados corroboram tal percepção, porém potencializam ainda mais as possibilidades de uso em sequências didáticas, uma vez que percebemos o livro infantil enquanto produto cultural, que pode se tornar um propulsor de questionamentos sociais acerca de temas variados. A análise contextual realizada demonstra ser uma etapa fundamental para identificar os temas presentes na narrativa, tanto das imagens quanto do texto escrito, permitindo que o olhar da professora esteja atento aos aspectos não necessariamente destacados ou percebidos em uma primeira leitura ou mesmo pelo próprio autor. É a leitura crítica e aprofundada da obra que permitirá a elaboração de questões norteadoras capazes de propiciar o en- 
caminhamento de temáticas, as quais nem sempre são apresentadas espontaneamente pelos alunos.

Compreendemos que o viés ideológico suscitado pelos diversos elementos culturais na produção de um texto apresenta concepções e maneiras de perceber o mundo aos seus receptores, contribuindo para o reforço ou a negação de mudanças sociais, assim como para a reprodução e a manutenção de determinados comportamentos. Os animais representados na história são construídos sob uma ambivalência entre os elementos da natureza real e a figurativização da narrativa, conduzindo a interpretações sobre temáticas científicas que possam ser levantadas.

Abordamos o livro infantil sob a perspectiva educacional e da arte considerada na relação dialógica entre o lúdico e a aprendizagem, o imaginário e o real, a ciência e a fantasia. Nessa perspectiva, nosso esforço consistiu em identificar e promover alguns encaminhamentos possíveis para um uso crítico do livro infantil, uma vez que, enquanto produto de uma cultura, este veicula determinadas visões referentes aos aspectos de gênero figurativizados nas personagens apresentadas e à relação com o outro e com o meio. Compreendemos, contudo, que outras abordagens, também com temas de ciências, podem ser desenvolvidas em atividades com o livro.

Considerando que a escola ocupa um lugar de significativa relevância social, dados o seu caráter de formação humana e a sua obrigatoriedade, é necessário estimular o desenvolvimento da habilidade de leitura e escrita, além de possibilitar situações problematizadoras que permitam despertar a compreensão de outras leituras possíveis das histórias, para além da descrita pelo autor, demonstrando aos alunos que nem sempre há apenas uma maneira de perceber os fatos. Nessa perspectiva, o livro infantil configura-se como um meio pelo qual é possível articular aspectos e conceitos dos âmbitos científico, linguístico e social.

Rosie's walk: articulating social and biological knowledge in childhood through literature

\begin{abstract}
In this paper, we seek to discuss a perspective of approaching social issues articulated to biologic knowledge in the childhood school by using children's storybooks as a didactic resource. We choose such kind of books since they are largely employed in teaching to this public. We present here a historical overview of this literature and then exemplify our proposal based on the greimasian semiotic analysis of a specific literary work of children's storybook, establishing, from this, different social themes that can be approached at the classroom context and relates to the day-to-day life of schoolchildren. Our analyzes demonstrate ambivalences between animal representations and scientific themes, but also in relation to the children's book as an educational object. Finally, we conclude that
\end{abstract}


an articulation of different knowledge fields for the development of an activity on a non-disciplinary basis contributes to a less compartmentalized education and a construction of a more articulated knowledge.

Keywords: Children's literature. Socio-scientific knowledge. Polyvalence.

\section{Referências}

BACHELARD, Gaston. O novo espírito científico. Rio de Janeiro: Tempo Brasileiro, 2000.

BAKER, Steve. Picturing the beast: animals, identity, and representation. Illinois: University of Illinois Press, 2001.

BARROS, Diana L. P. Teoria semiótica do texto. 4. ed. São Paulo: Ática, 2005.

BIZZO, Nélio. Ciências - fácil ou difícil? São Paulo: Biruta, 2009.

BRASIL. Ministério da Educação. Secretaria da Educação Fundamental. Parâmetros Curriculares Nacionais - Ciências Naturais. Brasília: MEC/SEF, 1997.

BUTZOW, Carol M.; BUTZOW, John W. Science through childrens literature: an integrated approach. 2. ed. New York: Libraries Unlimited, 2000.

CACHAPUZ, Antonio et al. A necessária renovação do ensino das ciências. São Paulo: Cortez, 2005.

CARVALHO, Fabiana A. A biologia em obras infantis de monteiro lobato: modulações literárias, científicas e culturais. Ciência \& Educação, Bauru, v. 14, n. 3, p. 467-82, 2008.

CHARPAK, George. As ciências na escola primária: uma proposta de ação. Sintra, Portugal: Inquérito, 1996.

COELHO, Nely N. Literatura infantil: teoria, análise e didática. São Paulo: Moderna, 2000.
COLOMER, Teresa. A formação do leitor literário: narrativa infantil e juvenil atual. São Paulo: Global, 2003.

DEITCH, Gene (Dir.). Rosie's walk. Vídeo. Cor. 4:36 min. Danbury, CT: Weston Woods Studios, 1970.

FISHER, Becky. Using literature to teach science. Journal of Research in Science Teaching, New York, v. 17, n. 2, p. 173-177, 1980.

GIRALDELLI, Carla G. C. M.; ALMEIDA, Maria J. P. M. Leitura coletiva de um texto de literatura infantil no ensino fundamental: algumas mediações pensando o ensino das ciências. Ensaio, Belo Horizonte, v. 10, n. 1, p. $1-18$, jun. 2008.

GLEDHILL, Ruth. Rosie's walk: a walking talking texts. Darwin, NT: Northern Territory Department of Education, 2003. Disponível em: $<$ http://is.gd/RZ8bBJ>. Acesso em: 09 jan. 2013.

GREIMAS, Algirdas J. Semântica estrutural. São Paulo: Cultrix; Edusp, 1973.

GREIMAS, Algirdas J.; COURTÉS, Joseph. Dicionário de semiótica. São Paulo: Contexto, 2008.

GOINS, Sheila L. Botany in children's literature: a content analysis of plant-centered children's picture books that have a plot and characters. Tese (Doutorado em Filosofia) - Baton Rouge, Graduate Faculty of the Louisiana State University, Agricultural and Mechanical College, 2004.

GUELFI, Maria Lúcia F. Literatura infantil fantasia que constrói realidades. Educação e Filosofia, Uberlândia, v. 10, n. 20, p. 131-154, jul./dez. 1996.

HARRISON, Debbie. Guided reading: Rosie's walk. Centreville, VA: London Towne Elementary School, 2001. Disponível em: $<$ http://is.gd/DbkhNV>. Acesso em: 09 jan. 2013. 
HIGASHI, Arlete M. F. Ciência e literatura em textos infantis de Angelo Machado. 2010. 127 f. Dissertação (Mestrado em Letras) Faculdade de Filosofia, Letras e Ciências Humanas, Universidade de São Paulo, São Paulo, 2010.

HUTCHINS, Pat. O passeio de Rosinha. São Paulo: Global, 2004. (Coleção Crianças Criativas).

KRASILCHIK, Myrian; MARANDINO, Marta. Ensino de ciências e cidadania. São Paulo: Moderna, 2004.

LAJOLO, Marisa; Zilberman, Regina. Literatura infantil brasileira: histórias \& histórias. 6. ed. São Paulo: Ática, 2007. (Série Fundamentos).

LERER, Seth. Children's literature: a reader's history, from Aesop to Harry Potter. Chicago: University of Chicago, 2008.

LINSINGEN, Luana Von. Literatura infantil no ensino de ciências: articulações a partir da análise de uma coleção de livros. 2008. 147 f. Dissertação (Mestrado) - Programa de Pós-Graduação em Educação Científica e Tecnológica, Universidade de Santa Catarina, Florianópolis, 2008.

MAGNANINI, Suzanne. Fairy-Tale Science: monstrous generation in the tales of Straparola and Basile. 2. ed. Toronto: University of Toronto Press, Scholarly Publishing Division, 2008.

MONHARDT, Rebecca; MONHARDT, Leigh. Children's literature and environmental issues: Heart over mind? Reading Horizons, Kalamazoo, v. 40, n. 3, p. 175-184, 2000.

Creating a context for the learning of science process skills through picture books. Early Childhood Education Journal, New York, v. 34, n. 1, p. 67-71, ago. 2006.

MORROW, Lesley M. et al. The effect of a literature-based program integrated into literacy and science instruction with children from diverse backgrounds. Reading Research
Quaterly, New Jersey, v. 32, n. 1, p. 54-76, Jan./Feb./Mar. 1997.

OWENS, Caroline V. Non-Sense, sense and science: misconceptions and illustrated trade books. Journal of Children's Literature, Chicago, v. 29, n. 1, p. 55-72, 2003.

PALO, Maria J.; OLIVEIRA, Maria R. D. Literatura infantil: voz de criança. 4. ed. São Paulo: Ática, 2006.

PAIVA, Jorge. O design da ilustração no livro ilustrado brasileiro contemporâneo. Dissertação (Mestrado em Design) - Programa de Pós-Graduação Stricto Sensu em Design, Universidade Anhembi Morumbi, São Paulo, 2012.

RICE, Diana. Using trade books in teaching elementary science: facts and fallacies. The Reading Teacher, New York, v. 55, n. 6, p. 552-655, Mar. 2002.

ROYCE, Christine A.; WILEY, David A. Children's literature and the teaching of science: possibilities and cautions. The Clearing House, New York, v. 70, n. 1, p. 18-20, Sept./Oct. 1996.

SACKES, Mesut; TRUNDLE, Kathy C.; FLEVARES, Lucia M. Using children's literature to teach standard-based science concepts in early years. Early Childhood Education Journal, New York, v. 36, n. 5, p. 415-422, Apr. 2009.

SMOLKIN, Laura B. Rosie's walk activity card. Charlottesville, VA: Curry School of Education (University of Virginia), 1999. Disponível em: <http://is.gd/moqPfx > . Acesso em: 09 jan. 2013.

SMARDO, Frances A. Using children's literature to clarify science concepts. The Reading Teacher, New York, v. 36, n. 3, p. 267-273, Dec. 1982.

WELLS, Rachael; ZEECE, Pauline D. My place in my world: literature for place-based environmental education. Early Childhood Education Journal, New York, v. 35, n. 3, p. 285-291, 2007. 
ZEECE, Pauline D. Animal antics in children's literature. Early Childhood Education Journal, New York, v. 26, n. 1, p. 35-38, 1998.

. Things of nature and the nature of things: natural science- based literature for young children. Early Childhood Education Journal, New York, v. 26, n. 3, p. 161-166, 1999a.

Building concepts with quality children's literature. Early Childhood Education Journal, New York, v. 27, n. 1, p. 35-39, 1999 b. 